analecta polit. | Vol. 9 | No. 16 | PP. 97-115 | enero-junio | 2019 | ISSN-e: 2390-0067 (en línea) |

Medellín-Colombia

doi: http://dx.doi.org/10.18566/apolit.v9n16.a06

\title{
Memoria. \\ De las versiones de la ciudad a la ciudad posible en el siglo XXI
}

Memory. From the versions of the city to the possible city in the 21st century

Memória. Das versões da cidade à cidade possível no século XXI

\section{ESMERALDA HINCAPIÉ}

Doctora en Ciencias Sociales

Docente titular de la Universidad Pontifica Bolivariana

(Medellín)

Correo electrónico: esmeralda.hincapie@upb.edu.co 


\section{Resumen}

El presente artículo analiza dos versiones de la memoria construidas sobre el desplazamiento forzado por el conflicto armado en Colombia: las versiones oficiales y las versiones reservadas de las víctimas. Se basa en los resultados de una investigación doctoral realizada durante los años 2012 a 2016 con personas desplazadas que llegaron a finales del siglo pasado a habitar asentamientos urbanos en la periferia de la ciudad de Medellín, que recrearon su vida y ahora se definen como nuevos nómadas, camaleónicos, tejedores de formas de convivencia interrumpida, efímera pero intensa, con encuentros al azar o en momentos clave de conexión necesaria para su supervivencia. La memoria de estas extrañas formas de estar y transitar por la ciudad, en la voz de las víctimas, es la base para sugerir políticas de la memoria que contribuyan a la reparación del daño, cuestionen la planeación moderna de la ciudad establecida y propongan ciudades que incluyan los modos de habitar recreados por los desplazados, coincidentes con los cambios espaciotemporales del siglo xxI, siglo del declive de las certidumbres.

Palabras clave: condiciones económicas, vivienda, asentamiento humano, acción comunitaria, planificación urbana, memoria colectiva.

\section{Abstract}

This article analyzes two versions of memory constructed upon forced displacement due to the armed conflict in Colombia: the official versions and the reserved versions of the victims. It is based on doctoral research results carried out from 2012 to 2016, with people displaced by the armed conflict at the end of the last century, who came to inhabit urban settlements in the periphery of the city of Medellín. These people now define themselves as new nomads and chameleonic subjects, weavers of interrupted coexistence forms, ephemeral but intense, with random encounters or in moments of necessary connection for their survival. The memory of these strange ways of being and traveling through the city is the basis for suggesting memory policies that contribute to repair damage, to question modern planning of the established city and to propose cities which include the ways of living recreated by the displaced. These spaces should coincide with the spatio-temporal changes of the 21 st century, the century of the decline of certainties.

Keywords: Economic conditions, housing, human settlements, community action, urban planning, collective memory. 


\section{Resumo}

O presente artigo analisa duas versōes da memória construída sob o deslocamento forçado pelo conflito armado na Colômbia: as versôes oficiais e as versôes reservadas das vítimas. Baseia-se nos resultados da pesquisa doutoral desenvolvida no período 2012 2016, com pessoas deslocadas pelo conflito armado aos finais do Século XX. Com pessoas deslocadas que chegaram a morar em assentamentos urbanos na periferia da cidade de Medellín, que recrearam sua vida. Hoje, eles definem-se como novos nômadas e sujeitos camaleônicos, tecedores de formas de convivência interrupta, efêmera, mas intensa, com encontros pela casualidade ou nos momentos de conexão necessária para sua supervivência. A memória destas estranhas formas de estar e transitar pela cidade é a base para sugerir políticas da memória. As quais contribuíam à reparação do prejuízo, questionem o planejamento moderno da cidade estabelecida e proponham cidades que incluam os modos de habitar inspirados pelos deslocados, coincidentes com os câmbios espaço-temporais do Século XXI, século do declive das incertezas.

Palavras-chave: condiçôes econômicas, moradia, assentamento humano, ação comunitária, planejamento urbano, memória coletiva. 


\section{Introducción}

Este artículo entiende la memoria como una práctica social y empieza por hacer una crítica a la memoria oficial sobre las víctimas del desplazamiento forzado que llegan a vivir en las periferias de la ciudad, en tanto es una memoria construida con manipulaciones discursivas para formar en la ciudadanía una visión negativa de esos asentamientos con el argumento de que ponen en riesgo el orden social. Estas manipulaciones se explican a lo largo del texto como un "abuso de memoria" que tiene la finalidad de legitimar intervenciones gubernamentales en las que las víctimas son identificadas como culpables de los problemas de la ciudad, ocultando y aplazando con ello la obligación de repararlas y restituirlas como sujetos de derecho y protección.

Con base en lo anterior, el artículo señala la importancia de entender y atender las versiones de las víctimas, no solo de las que se organizan para reivindicar sus derechos a la reparación y a la restitución de condiciones para volver a la estabilidad perdida, sino de las "memorias reservadas" de víctimas que tienen que recrear su vida en el día a día para poder sobrevivir, recreación que da lugar a nuevas formas de ser y estar en la ciudad, y que pueden convertirse en la oportunidad para que los científicos sociales entiendan la vida en la "incertidumbre", problema al que se ven enfrentadas las generaciones del siglo Xxi.

La primera categoría que estructura este texto, el "abuso de memoria", se entiende como una manipulación abusiva del discurso (Ricoeur, 2004) integrada al campo de las teorías de la memoria, memoria entendida como versión de hechos pasados construida en el presente, en escenarios y con mediaciones que dan forma a testimonios y olvidos de sujetos situados históricamente en determinadas posiciones de poder. Los que se ubican en posiciones privilegiadas controlan los medios de comunicación y definen las formas de narración específicas de lo sucedido, para inducir interpretaciones acordes con sus intereses con efectos políticos y de poder; esta inducción es la que conduce a la línea de investigación sobre los abusos de la memoria.

En la línea de los "abusos de la memoria", las investigaciones recientes retoman autores que a principios de este siglo señalaron los riesgos que engendran los discursos políticos y oficiales en las prácticas conmemorativas (Vázquez, 2001; Ricoeur, 2004), y muestran casos de uso abusivo de los testimonios de las personas en riesgo para manipular la sensibilidad de la sociedad con efectos de espectáculo y banalización del sufrimiento (Montoya, 2012; Castillejo, 2013) para 
legitimar decisiones políticas que van en contra de las víctimas (Amaya, Perdomo \& Ortiz, 2013) y para justificar la guerra (MOVICE, FCSPP, CCAJAR, 2009; GMH, 2011; Blair, 2011; Uribe, 2011; Rieff, 2012; Centro Nacional de Memoria Histórica, 2013).

En el caso de la construcción de la versión oficial de la ciudad, que afirma el ideal del orden social, estas manipulaciones discursivas logran formar en la ciudadanía una visión negativa de los asentamientos urbanos y una visión dicotómica de la ciudad que separan la ciudad formal de la informal, desconociendo su diversidad y complejidad (Montejano, 2008; Castillejo, 2013; Girón, 2013; Grupo Lazos Sociales y Culturas de Paz, 2014). Esa mirada convencional legitima la conversión de las políticas de prevención y protección en políticas de desalojo, difunde versiones manipuladas de los riesgos que viven los desplazados para presentar los desalojos como intervenciones urbanistas de protección de la vida basada en políticas de inclusión y bienestar social, y de éxito en la normalización de la ciudad (Blair, 2011; Acevedo, 2012; Cabrera, 2013; Girón, 2013).

La segunda categoría, "memorias reservadas", es la memoria del día a día de las víctimas, prácticas sociales de comunidades expulsadas de sus territorios, barrios y viviendas, que enfrentan condiciones de inestabilidad espaciotemporal prolongada e improvisan asentamientos en terrenos inestables de las grandes ciudades bajo la amenaza constante de desastres, conflictos armados, bandas criminales y desalojos, forzadas a tomar decisiones súbitas, hacer cambios bruscos, estar al acecho, y moverse o camuflarse para hacerse invisibles, no localizables, no identificables.

En estas condiciones de vida y en sus modos de enfrentarlas, el hallazgo principal de la investigación en la que se basa este artículo es el conocimiento que estas personas tienen para vivir en la incertidumbre y convivir en la diversidad, conocimiento que problematiza los presupuestos sobre los que se define el orden de la ciudad, los límites de este orden y el abuso de la memoria construida por el discurso oficial para hacer culpables a las personas que viven en los asentamientos de poner en riesgo este orden.

Este conocimiento borra las divisiones y trasciende la idea clásica de tiempo para proponer transformaciones a las visiones modernas de habitar la ciudad, invita a proponer políticas de la memoria que lo hagan visible, pues tras ello hay una alternativa potente que puede ayudar a las sociedades a dar el salto de una realidad basada en la certeza y el orden, construida durante más de quinientos años, hacia una realidad basada en la incertidumbre que está abriendo el siglo XXI. 
La relevancia teórica de investigar críticamente el poder de las versiones oficiales para abusar de la memoria y la potencia que hay en las versiones reservadas de las víctimas para generar alternativas de transformación de la ciudad se puede resumir en tres premisas: primero, es una oportunidad para construir nuevas categorías que permitan entender los escenarios de conflicto en el siglo XXI, configurados por intereses y actores que se están dislocando de los lugares conocidos en siglos pasados, con borrosas posiciones y actuaciones. Segundo, Colombia es un laboratorio para entender cierto tipo de dislocaciones y ellas podrían ser un ejemplo para explicar el ingreso de las sociedades al siglo de la incertidumbre, ya anunciado por científicos como Immanuel Wallerstein e Ilya Prigogine. Y tercero, los cambios en los escenarios de conflicto muestran la potencia creativa de quienes comúnmente son vistos como víctimas pasivas.

\section{Conceptos}

Este artículo contextualiza las teorías de la memoria en la vida de las ciudades del siglo xxi, siglo que es planteado por distintos teóricos como un momento de crisis que está desestabilizando o dislocando a los sujetos, el tiempo y el espacio (Wallerstein, 1999; Pécaut, 2004; Prigogyne, 2006). A continuación, se precisan los conceptos elegidos de la teoría de la memoria y de la vida en la ciudad en este cambio de siglo.

Las tres premisas de la teoría de la memoria que fundamentan el análisis de las versiones oficiales y reservadas de la ciudad son:

- La memoria es una práctica social de sujetos situados históricamente, que construyen en el presente versiones de experiencias pasadas y que tienen distintas posiciones de poder desde las que inducen concepciones y fines de la memoria, al definir formas de narración específicas de lo sucedido (Vázquez, 2001; Piper, Fernández e Íñiguez, 2013).

- El abuso de memoria es una instrumentalización y dirección abusiva de la memoria que usa estrategias de manipulación de situaciones vividas y testimonios para ofrecer una sensibilidad con efectos de espectáculo que banaliza el sufrimiento, presente en discursos políticos oficiales y en prácticas conmemorativas para definir, legitimar y justificar decisiones, como las de guerra y desalojos (Ricoeur, 2004).

- Las memorias reservadas de las víctimas deconstruyen los abusos de memoria (Acevedo, 2012). 
Para contextualizar la teoría de la memoria en el siglo xxI y mostrar los efectos del cambio de siglo en la vida de las ciudades, se toman tres conceptos:

- El concepto de "expulsión", propuesto por Saskia Sassen en 2015 para indicar la diferencia con relación al concepto de "exclusión" usado en el siglo xx. Sassen dice que, en el nuevo sistema económico global, la expulsión es una forma brutal de eliminación de lo humano que causa migraciones de personas y comunidades que le estorban al sistema, que ya no le hacen falta ni como productoras ni como consumidoras, y usa mecanismos financieros de matemática compleja para hacer desaparecer a los responsables. Estas expulsiones aceleran el crecimiento urbano debido a la formación de asentamientos que adquieren nuevas características y modifican las tendencias de modernización de las ciudades en manos de los urbanistas privados.

- El concepto de "diversidad", de convivencia compleja en la diversidad, identificado por psicólogos y educadores comunitarios como Maritza Montero (2010a, 2010b), permite mostrar que los asentamientos urbanos en el siglo XXI y en Colombia ya no tienen las mismas características que tenían los del siglo pasado, hechos por los colonos o las familias campesinas antes de los años ochenta.

- El concepto de "incertidumbre", trabajado para el contexto de los cambios sociales por Wallerstein $(1999,2006)$ en compañía del análisis del tiempo en la teoría de Ilya Prigogine (2006). La vida en la incertidumbre es un rasgo que prima en los asentamientos urbanos del siglo xxi; dadas las condiciones de inestabilidad prolongada a las que son sometidas las víctimas del conflicto armado, sus respuestas a esta incertidumbre ponen en cuestión los presupuestos de estabilidad y equilibrio en los que se basó la planeación moderna y el desarrollo de las ciudades.

\section{Método}

La investigación de la que sale este artículo se realizó en asentamientos urbanos formados en el occidente de Medellín a partir de 1997 y reubicados entre 2003 y 2005 (Vallejuelos, Olaya Herrera, La Arenera, El Pesebre, Las Torres y Blanquizal). En estos asentamientos vivieron comunidades que estuvieron en condiciones de riesgo extremo desde que fueron desplazadas en los años noventa, que llegaron de muchas partes del país a la ciudad y fueron capaces de cuestionar el orden establecido, resistirse a los desalojos, negociar una reubicación integral y transformar Planes de Ordenamiento Territorial (рОт), proyectos viales y políticas de vivienda. Las características específicas de estas comunidades permiten ponerlas 
en diálogo con los conceptos de "expulsión" y "diversidad", definidos en el apartado anterior ${ }^{1}$.

A partir de esta experiencia se diseñó un estudio de caso en el que se organizaron distintos grupos de participantes que cumplieran con la condición de haber vivido todo el proceso de desplazamiento, asentamiento y reubicación, en su rol de víctimas, líderes de la organización comunitaria, organizaciones de apoyo y defensa de derechos humanos, y gobierno al frente de este problema. Sus narraciones o versiones de la ciudad se contrastaron con investigaciones previas del caso, con la experiencia allí vivida por la investigadora y con las versiones de las organizaciones religiosas que vivieron en estos asentamientos desde 1997 (Hermanas Carmelitas Misioneras y Hermanos Franciscanos Misioneros).

La "versión oficial" fue construida con los informes oficiales de la administración pública, con entrevistas a funcionarios públicos que participaron del proceso de atención a los asentamientos urbanos desde los años noventa hasta las reubicaciones posteriores al año 2000, con entrevistas a dirigentes políticos implicados y con entrevistas a urbanistas privados que participaron en la construcción de alternativas de vivienda en los procesos de reubicación. No fue posible entrevistar a los dueños de las tierras aledańas a los terrenos donde se reubicaron estas comunidades, pero se tuvo en cuenta su oposición a estos traslados, dado el cambio en el uso del suelo que afectó sus planes económicos, como está consignado en los informes oficiales. En esta versión, los problemas de la ciudad se localizan en los habitantes de los asentamientos, priman discursos de protección de la vida para legitimar desalojos, políticas de vivienda y reubicaciones que muchas veces parecen estar más al servicio de los urbanistas privados que al servicio de las comunidades, tal como lo exige el cumplimiento de las funciones del Estado.

La "versión de las comunidades" fue construida en talleres grupales y entrevistas individuales, hasta lograr descripciones amplias y detalladas sobre las condiciones de vida en los asentamientos urbanos, sus resistencias y transformaciones de cara a los desplazamientos, desalojos, desastres, enfrentamientos armados, las negociaciones y los problemas comunitarios entre 1997 y 2012. Aquí es necesario diferenciar dos narrativas:

- Las "memorias reivindicativas de derechos", en la voz de los grupos de líderes que ven en la intervención gubernamental una mentira institucionalizada,

1 Para una descripción detallada de estas comunidades y sus narraciones, consúltese el libro Comunidades transformadoras de cuidad (2019). 
legitimada por el abuso de memoria que fabrican. Son líderes que participaron en movilizaciones sociales para ganar el derecho a la reubicación; en ellos priman discursos reivindicativos de sus derechos, apoyados por movimientos sociales y organizaciones no gubernamentales, prima una memoria que describe sus logros como organización comunitaria: cierta autonomía respecto a los actores armados y la administración pública, la resistencia a los desalojos, la sobrevivencia a los desastres y a los enfrentamientos armados, la gestión para cambiar el рот de Medellín, cambiar las políticas de desalojo por políticas de reubicación, así como los conflictos y el desgaste del trabajo comunitario.

- Las "memorias reservadas" (Acevedo, 2012), que salieron en las entrevistas individuales y en los momentos de reflexión grupal sobre el sentido y cambio de sus vidas, cuando habla en ellos la persona, más que el líder. Al respecto, es pertinente anotar que aquí también participaron personas que siempre estuvieron al margen de la organización comunitaria y la gestión gubernamental. Esta es una narrativa diferente que resulta en dos circunstancias diferentes: cuando son cuestionados por los excesos de su intermitencia, transitoriedad e incapacidad para cumplir la planeación de las entrevistas, los talleres y los eventos comunitarios, y cuando reflexionan sobre una nueva forma de vivir que se juega en una serie aleatoria de momentos críticos, momentos que los hace conscientes de la imposibilidad de planear en el tiempo y los va llevando a desarrollar ciertas habilidades tácticas para soportar la incertidumbre, hacerla su aliada, o, como dicen ellos, para hacerse "camaleónicos"2.

Por la ruta de las memorias reservadas se fue captando el sentido de su inestabilidad y sus tácticas para vivir en la diversidad, se fueron identificando los rasgos de una subjetividad emergente que responde a las razones por las cuales sienten que no caben en el orden convencional establecido por la ciudad, que no quieren entrar en él y que, por el contrario, le proponen otros órdenes paralelos. En este punto, la información recogida entró en diálogo con el concepto de "incertidumbre".

\section{Resultados}

Es común encontrar, en las investigaciones, visiones de la realidad que entienden la tensión entre posturas diferentes como dicotomía; esto se ve en los debates entre los discursos de las memorias oficiales y las reivindicativas, también en los aná-

2 Para conocer estas narrativas, consúltese el libro de la tesis doctoral: Comunidades transformadoras de ciudad. 
lisis que avanzan un poco más y llegan a proponer alternativas de diálogo entre ambas posiciones, e incluso en los análisis con perspectiva dialéctica que, aunque critican las dicotomías y promueven el cambio, terminan en propuestas que recuperan cierto orden. La gran mayoría de estas investigaciones no escapan al sello de una racionalidad moderna que defiende el orden, busca la certeza y promete estabilidad. Un caso típico del uso de estas investigaciones para legitimar su visión de la realidad es la postura de los discursos oficiales, que, como salvaguarda de la institucionalidad, hacen de su función social la defensa de lo establecido y por lo tanto rechazan todo lo que represente incertidumbre e inestabilidad.

Este artículo adopta una postura diferente, al presentar resultados de una investigación que se arriesga a pensar lo social en el contexto de los cambios, las perspectivas y los conceptos del siglo xxI; es por ello que, desde la perspectiva de la complejidad, abre la pregunta por el espacio-tiempo de la vida en la ciudad y se encuentra con la necesidad de abandonar la idea de "tensión" del siglo pasado para pensarla como oportunidad de flexibilidad gracias a la diversidad. Este modo de investigar abrió un camino de propuestas para otras ciudades posibles, camino que siguió las huellas de los estilos de vida de los expulsados (desplazados) que incorporan la incertidumbre.

Es por lo anterior que, en esta parte de los resultados, se presentan las dos formas de entender la tensión en las maneras de ver la ciudad: la primera forma es típica del siglo pasado y conduce a adoptar posturas dicotómicas y la segunda es la que propone esta investigación para entender la vida en la incertidumbre y la convivencia en la diversidad.

\section{La tensión como dicotomía y ruptura}

Hay una forma de vivir la tensión entre distintos modos de ver y vivir la ciudad que exige el sometimiento de una de las partes o la confrontación hasta llegar a las rupturas. Es el caso del enfrentamiento entre la perspectiva oficial del Gobierno, que debe poner orden en la ciudad y defender la vida, y la perspectiva de las comunidades de los asentamientos urbanos, que construyen otro orden y también defienden sus vidas. Lo nuevo es que las condiciones del siglo XXI introducen, al interior de cada una de estas posturas, paradojas que es importante señalar.

La paradoja del Gobierno radica en tener que atender a expulsados y depender de los expulsores: debe ejercer su función social como protector de la vida 
de quienes fueron expulsados de sus territorios y tiene que ser anfitrión de los expulsores para garantizar la sostenibilidad económica de la administración de la ciudad. Mientras ejecuta políticas de atención a la población desplazada en la ciudad para incluirla en el orden establecido, ese mismo orden es el que está expulsando a más y más gente de los territorios, porque está dirigido por los capitales expulsores, los mismos de los que depende el sostenimiento de la ciudad.

La paradoja de las comunidades expulsadas radica en organizarse para luchar por la restitución de sus derechos, pero a la vez tener que renunciar a ellos porque estos derechos se juegan en un sistema que ya no responde a sus modos de vida: hacen memoria para que no se repita el daño y les restituyan sus derechos, pero el peligro que engendra esta lucha en los territorios los obliga a aislarse de un Gobierno en el que no confían porque depende del sistema económico que los expulsó y porque la oferta "adaptacionista" gubernamental no responde a su nueva vida, construida durante años de inestabilidad en medio del riesgo, lo que los obliga a volverse invisibles, cambiar con cada interlocutor y moverse constantemente para no ser localizados, en una vida en la que ellos mismos se definen como "camaleónicos" para lograr un poco de autonomía.

En este juego paradojal, el discurso oficial dirige de manera abusiva la memoria para construir una imagen tergiversada de la realidad, para estigmatizar a las comunidades de los nuevos asentamientos urbanos y que además funciona como "una política de localización" (Brah, 2011) que desplaza hacia estas comunidades las deficiencias de la ciudad y los problemas estructurales de la sociedad.

Son dos los mecanismos que se ponen en funcionamiento en esta operación: tergiversación y estigmatización. En el primero, se les otorga a las personas la identidad grupal de ser pobres, y en el segundo, se conecta esta identidad con los siguientes rasgos:

- El crimen, para acentuar y justificar las diferencias de clase.

- La mendicidad, ingratitud y pereza, para encubrir con falso altruismo la corrupción que sostiene una profunda inequidad de oportunidades.

- El miedo al extraño por su maldad, que justifica el racismo como estrategia de exclusión.

Esta realidad de los asentamientos así construida por el discurso oficial es deconstruida por algunos miembros de comunidades que logran deslocalizarse de esta identidad y ver las cosas desde otros lugares. Una muestra de este proceso de deconstrucción se presenta en las dos tablas siguientes, elaboradas como una sín- 


\section{8 | Esmeralda Hincapié}

Memoria. De las versiones de la ciudad a la ciudad posible en el siglo XXI

tesis de varios talleres realizados con grupos de líderes comunitarios del occidente de Medellín en 2015.

La primera tabla es un ejemplo del mecanismo de la tergiversación: en la primera columna se seleccionaron las principales frases de funcionarios públicos que representan el discurso aparente de la función protectora del Estado y en la segunda se seleccionaron las principales interpretaciones que los líderes dan a esas frases y prácticas establecidas, y muestran en ellas la tergiversación de la función.

Tabla 1 Tergiversar

\begin{tabular}{ll}
\hline Prácticas establecidas & \multicolumn{1}{c}{ Tergiversación de las prácticas establecidas } \\
\hline $\begin{array}{l}\text { Prevenir que se } \\
\text { formen asentamientos } \\
\text { irregulares y proteger } \\
\text { la vida }\end{array}$ & $\begin{array}{l}\text { Dejan que se formen asentamientos porque están } \\
\text { dedicados a administrar y a hacer crecer la ciudad formal. } \\
\text { Su manera de prevenir es con acciones violentas: los } \\
\text { desalojos. }\end{array}$ \\
& $\begin{array}{l}\text { Esperan a que haya desastres para darse cuenta de que los } \\
\text { riesgos existen. }\end{array}$ \\
& - Solo hacen obras de mitigación donde están los ricos. \\
\hline $\begin{array}{l}\text { Ofrecer alternativas de } \\
\text { reubicación planeadas } \\
\text { con la gente }\end{array}$ & $\begin{array}{l}\text { Las reubicaciones no son una oferta ni una alternativa del } \\
\text { Gobierno, son un logro comunitario contra el desalojo. }\end{array}$ \\
& $\begin{array}{l}\text { La planeación del Gobierno no atiende a la lógica de la vida } \\
\text { cotidiana de las comunidades, entonces termina generando } \\
\text { problemas peores. }\end{array}$ \\
\hline $\begin{array}{l}\text { Facilitar el acceso a } \\
\text { viviendas dignas. }\end{array}$ & $\begin{array}{l}\text { Las modalidades de vivienda entregadas en las últimas } \\
\text { décadas no son dignas. }\end{array}$ \\
$\begin{array}{l}\text { Proyectos integrales y } \\
\text { terminados. }\end{array}$ & $\begin{array}{l}\text { Nunca son integrales. } \\
\text { No los terminan; de esta manera, los espacios ganados } \\
\text { con trabajo comunitario terminan en manos de urbanistas } \\
\text { privados. }\end{array}$ \\
\hline
\end{tabular}

Fuente: Elaboración propia.

La segunda tabla muestra el mecanismo de estigmatización construido a partir de la tergiversación. En la primera columna están los enunciados más frecuentes de los funcionarios públicos sobre las personas que viven en los asentamientos, a los que les otorgan una identidad a partir de la condición de pobreza (prejuicio) para conectar atributos generalizados (prejuicios) con efectos sociales negativos sobre su imagen (discriminación), forma de abuso de la memoria que opera como política de localización. En la segunda columna está la deconstrucción de estos enunciados realizada por las personas de la comunidad, lo que devela el sentido oculto de los mismos y pone en cuestión la validez de las prácticas. 
Tabla 2 Estigmatizar

\begin{tabular}{ll}
\hline $\begin{array}{c}\text { Prejuicios - estereotipo - } \\
\text { estigmatización }\end{array}$ & \multicolumn{1}{c}{$\begin{array}{c}\text { Deconstrucción de prejuicios - } \\
\text { estereotipo - estigmatización }\end{array}$} \\
\hline $\begin{array}{l}\text { Quien vive allí es porque } \\
\text { ha pagado a piratas, esto } \\
\text { quiere decir que está en un } \\
\text { mercado de suelo irregular } \\
\text { e ilegal }\end{array}$ & $\begin{array}{l}\text { Es cierto que en esos terrenos hay quienes lotean y venden, } \\
\text { pero ipor qué ejecutan sus acciones contra quienes viven allí } \\
\text { criminales para las que el Estado y contra esas organizaciones } \\
\text { declara incapaz? }\end{array}$ \\
\hline $\begin{array}{l}\text { La gente se organiza para } \\
\text { resistirse a las autoridades pasiva o se }\end{array}$ & $\begin{array}{l}\text { La gente se organiza para resistirse a la violencia de Estado, el } \\
\text { mismo que debería proteger sus vidas }\end{array}$ \\
\hline
\end{tabular}

Los desalojos se hacen para cuidar sus vidas, pero no entienden

Los desalojos no son para proteger la vida, los hacen cuando necesitan el terreno o cuando hay desastres; la mayoría de las veces expulsan y no les importa a dónde vamos, solo cuando hay comunidades organizadas les exigen el respeto a la vida y alguna alternativa.

Organizarlas es

difícil porque son comunidades que cambian continuamente
Las comunidades están en permanente cambio porque están en permanente riesgo e inseguridad. La intervención del Estado no corresponde a ese dinamismo y complejidad; por el contrario, la inestabilidad la asimila a inseguridad y la atiende con desalojos, eso genera mayor inseguridad.

No hay prevención porque hay pasividad de las autoridades. No actúan por planeación para dar soluciones o prevenir desastres, sino que esperan los desastres o los conflictos.
Aprenden a evadir la ley por su experiencia en la ocupación de tierras. Las autoridades se muestran impotentes para prevenirlo.

El desarrollo de proyectos no se cumple por las disputas. Estas pueden ocurrir durante la implementación de los programas acordados con las autoridades y durante el funcionamiento pleno del mismo.

Los repartos equitativos son difíciles de establecer porque las relaciones con las autoridades no son reguladas

Muchos proyectos no tienen los resultados deseados debido a la complejidad de esta situación
El motivo de las disputas es, la mayoría de las veces, por el incumplimiento de los acuerdos negociados durante años de lucha desigual, de las organizaciones comunitarias con las autoridades. Es muy difícil llevarlos a los acuerdos y luego hacer que cumplan. Eso conduce a las organizaciones comunitarias al desgaste y a la confrontación interna, y ellos lo saben y esperan que eso pase para poner la culpa en nosotros.

Las negociaciones son acuerdos pactados, pero las autoridades están acostumbradas a actuar por normas y no por ley. Los repartos equitativos que proclaman son la repartición de la pobreza, pues los umbrales de lo digno en la inversión son suprahumanos, porque prima la ganancia de los urbanistas, a quienes además se les hace una interventoría inadecuada.

Los resultados deseados por las autoridades son: limpiar los terrenos de gente indeseable, llevarla a urbanizaciones lejanas donde no estorben y, si logran terrenos cercanos, aislarlos hasta hacerlos aburrir y ocultar estas verdaderas intenciones diciendo "cumplimos", en actos espectaculares de entrega de apartamentos y rendición de cuentas.

Fuente: Elaboración propia. 
En síntesis, esta tensión entre las versiones de la memoria, dicotómicas, opuestas y polarizadas, muestra prácticas sociales tras las que se mueven discursos oficiales que funcionan como políticas de localización, que usan estrategias de tergiversación y estigmatización para justificar la expulsión y a las que se oponen prácticas comunitarias, muchas de sometimiento, resignación y adaptación, y algunas pocas de resistencia que terminan en rupturas con el sector oficial.

\section{La tensión como diversidad y flexibilidad}

Interpretar la tensión entre dos versiones de la memoria de manera dicotómica oculta nuevas realidades que están trascendiendo la oposición. Además de una versión que representa el discurso institucional determinado por los sistemas de poder y las estructuras que lo sustentan, y otra que representa al actor expulsado que genera otras formas de estar en la sombra, en el borde del sistema, lo que interesa aquí es la emergencia de otras interpretaciones que están construyendo otras subjetividades y formas de habitar la ciudad en el escenario del siglo xxI, con tácticas que parecen emerger en momentos de incertidumbre.

Esto exige cambiar la perspectiva después de revisar los fundamentos epistemológicos del conocimiento moderno. Una mirada renovada y atenta a los cambios del siglo XXI puede ayudar a reinterpretar la realidad de las comunidades que viven en nuevos asentamientos urbanos y a criticar el orden impuesto de la ciudad establecida. Es una oportunidad para entender cómo viven las personas con el miedo y qué hacen con él para salvarse de los desastres, los actores armados y los desalojos, cómo emerge la creatividad en momentos de crisis que las llevan a hacer cosas jamás imaginadas, en fin, es una oportunidad para entender lo que hay de fundamento en sus nuevos estilos de vida, tal vez no comprendido por ellas mismas pero actuado: eso emergente, imprevisto y crítico es tal vez una ruta para entender cómo se están configurando otras ciudades posibles.

Los presupuestos modernos de orden, fundados en las ideas de espacio y tiempo de la física clásica (Newton, 1660) y trasladados a las ciencias sociales como marco de referencia de la realidad social, están siendo refutados por las ciencias de la complejidad y las teorías contemporáneas de la cultura; en consecuencia, las ideas de sociedades estables, homogéneas y ordenadas también están siendo refutadas. Para entender este cambio en la racionalidad moderna al finalizar el siglo xx, la comisión Gulbenkian invitó a "abrir” las ciencias sociales (Wallerstein, 
1996): siguiendo esta invitación, lo que hizo esta investigación fue estudiar las tácticas de estas comunidades para vivir en la inestabilidad y por fuera del orden establecido, pues, al parecer, ellas cuestionan el presupuesto del espacio y el tiempo como determinantes y marco de lo social. En términos teóricos, esto significa proponer el espacio-tiempo como posibilidad.

Tal vez la dificultad para comprender lo que está emergiendo en las nuevas formas de estar en la ciudad radica en la resistencia a dudar de los presupuestos epistemológicos que marcaron el pensamiento moderno, basado en los presupuestos de orden, espacio y tiempo, algunos de cuyos efectos fueron la división entre hombre y naturaleza, la división del conocimiento en campos, la división entre realidad física y social, etc. La invitación, aquí, es a superar todas estas divisiones para ensayar otros modos de asumir nuestra comprensión de la realidad, superando los presupuestos de orden (estabilidad) y verdad (certeza). Esto es una condición para entender que, precisamente, es la inestabilidad la que impide la ruptura cuando hay tensión y que es la diversidad la que resuelve la polaridad de las partes en confrontación.

Si estos presupuestos se toman en serio, podría afirmarse que:

- Están emergiendo nuevas formas de hacer comunidad, por conexiones instantáneas y no previstas, entre extraños que llegan de todas partes a enfrentar situaciones de riesgo.

- Están configurándose nuevas formas de subjetividad al adquirir las personas una potencia creativa para construir nuevas formas de vivir, relacionarse y estar en la ciudad, mientras superan expulsiones, conflictos armados, deslizamientos o incendios.

- Se está respondiendo a la lógica de la estrategia de localización con la lógica de las tácticas de deslocalización (De Certeau, 2007; Brah, 2011) como forma de actuación que da cierta autonomía a los expulsados del sistema respecto al orden establecido; en el caso de los asentamientos, esto parece mostrarse como modos "camaleónicos" de estar en la ciudad.

Este cambio de perspectiva da un nuevo sentido a la comprensión de la diversidad y la inestabilidad que la caracteriza. La diversidad da un nuevo sentido de lo comunitario cuando la inestabilidad hace del otro el garante de la propia vida y a la vez el peligro; por ello la convivencia opera por conexión entre actores que se transforman y mueven continuamente. Al parecer, una alternativa a la fragmentación cultural inducida por las expulsiones que aglomera a gente de di- 


\section{2 | Esmeralda Hincapié}

Memoria. De las versiones de la ciudad a la ciudad posible en el siglo XXI

versas culturas es el sistema de conexiones instantáneas, lo cual exige reinterpretar la pertinencia de una epistemología de la relación y de una ética de la otredad (Montero, 2010) y reinterpretar la interculturalidad como antídoto contra el "divide y gobernarás", en tanto potencia "el diálogo crítico entre las culturas y de las culturas unidas en la diversidad" (Freire, 1992, p.157).

Efectivamente, estas comunidades en riesgo constante van formando una ética de la relación en la que el otro se hace un nosotros (Montero, 2010b), en la que un sentimiento de comunidad les hace ser, tomar y tener parte (2010a), pero en situaciones de incertidumbre estas relaciones son tan intensas como instantáneas, emergen en momentos de crisis y aparentan ser aglomeraciones caóticas, pero son libres de desaparecer y reaparecer. Ver las cosas de esta manera y entender esta propuesta implica por lo menos dos cosas.

En primer lugar, implica reconsiderar la idea de espacio-tiempo: como lo senala Wallerstein (2006), fue necesario que las ciencias naturales cuestionaran el concepto clásico de espacio y tiempo (reversibilidad, ambición de cálculo y certeza, objetividad y orden), el mismo que excluyó al sujeto contingente, para que las ciencias sociales recordaran al hombre común y corriente, al del sentido común y la experiencia cotidiana, al impredecible, transitorio, al que deviene, al que se contradice porque es múltiple, al que estudian las humanidades, al que narra la literatura. En esta perspectiva, escribir una memoria de la ciudad que dé cuenta de sus movimientos y riesgos, de vidas que dislocan subjetividades entre desastres, desalojos y reubicaciones, puede ayudar a entender la dislocación de los presupuestos espaciotemporales (Pécaut, 2004).

En segundo lugar, implica unir la diversidad a la inestabilidad: el crecimiento acelerado de las ciudades engendra la lucha por los espacios, pero es una lucha entre poderes y micropoderes que las personas asumen como una forma de estar en una ciudad que los acecha, en la que se hacen invisibles para estar también al acecho. La memoria de la ciudad posible se refiere a esas formas paralelas de entenderla y habitarla, dispersión, falta de centro, imposible unidad, inestabilidad; "lo efímero, fugaz y evanescente de la vida urbana [...], su carácter performativo [...], la ciudad que se hace al tenor de un cambio de piel constante" (Rojas, 2015, pp. 140-144). Esta unión es una fuente de investigación para avanzar en la comprensión de las consecuencias sociales del declive de las certidumbres (Wallerstein, 1997, 1999, 2006; Prigogine, 2006). 


\section{Conclusión}

Encontrar otras visiones de ciudad en las memorias reservadas pone en evidencia los límites de la planeación moderna de la ciudad e invita a incluir los cambios espaciotemporales que está causando el mundo contemporáneo. Estas visiones se encuentran en la potencia de quienes aprenden a transitar por la ciudad después de ser expulsados, desalojados de los asentamientos, reubicados y sometidos a enfrentamientos armados, entre muchos otros riesgos. Estas comunidades demuestran que la posibilidad de construir ciudades por donde transite la vida y su potencia transformadora radica en que seamos capaces de estar en la inestabilidad y conectarnos en la diversidad. Para estas comunidades, la expulsión significó perder toda referencia y ello los empujó a encontrar en la inestabilidad una alternativa de vida. Pasaron de vivir en lo cierto, determinado o planeado, a entender que la vida también es pluralidad de posibilidades y se extiende en el tiempo, que significa "estar siendo", que significa "saber estar en la incertidumbre".

Profundizar en otra comprensión de la memoria, por fuera de sus clásicos marcos sociales de espacio y tiempo, es entender que si bien la memoria es acción (Vázquez, 2001), es fundamentalmente contingente, y esto es entender que la vida va de la mano con la incertidumbre, no con el recuerdo fijado en un pasado ni repetido en un futuro. Muestra también formas diferentes de entender lo comunitario y la ciudad: lo comunitario existe por las conexiones instantáneas, fuertes y no previstas entre extraños, y estar en la ciudad con cierta autonomía respecto del orden establecido es posible por tácticas de deslocalización que las personas llaman "modos camaleónicos de estar" (Brah, 2011).

Por todo lo anterior, este texto es una invitación a entender y participar en estas ciudades posibles como nuevos actores, a seguir la propuesta de Wallerstein (1996) de investigar los efectos sociales y psicológicos del declive de las certidumbres en el siglo XXI, a aceptar las posibilidades de investigación que se abren con estos nuevos presupuestos de los marcos de la memoria, ya no de espacio y tiempo, sino de espacio-tiempo.

\section{Referencias}

Acevedo, O. F. (2012). Geografías de la memoria. Posiciones de las víctimas en Colombia en el periodo de justicia transicional (2005-2010). Bogotá: Pontificia Universidad Javeriana. 
114 | Esmeralda Hincapié

Memoria. De las versiones de la ciudad a la ciudad posible en el siglo XXI

Amaya, S.; Perdomo, E. \& Ortiz, A. (2013). Reflexiones a tres voces: memorias de costal. En A. Castillejo \& F. L. Rodríguez (eds.), Violencia, memoria y sociedad: debates y agendas en la Colombia actual (pp. 83-93). Bogotá: USTA.

Blair, E. (2011). Micropolíticas de la(s) memoria(s). El sentido político de la dignidad. Desde la REGIÓN: Memoria, (54), pp. 19-30.

Brah, A. (2011). Cartografías de la diáspora. Identidades en cuestión. Madrid: Traficantes de Sueños.

Cabrera, M. (2013). Espectáculos del Estado: visibilizando al enemigo en la seguridad democrática. En A. Castillejo \& F. L. Rodríguez (eds.), Violencia, memoria y sociedad: debates y agendas en la Colombia actual (pp. 67-81). Bogotá: USTA.

Castillejo, A. (2013). La ilusión de la palabra liberadora: hacia una política del testimoniar en Colombia. En A. Castillejo \& F. L. Rodríguez (eds.), Violencia, memoria y sociedad: debates y agendas en la Colombia actual (pp. 21-28). Bogotá: USTA.

Centro Nacional de Memoria Histórica (2013). ¡Basta ya! Colombia: Memorias de guerra y dignidad. Recuperado de http://www.centrodememoriahistorica.gov.co/micrositios/informeGeneral/.

De Certeau, M. (2007). La invención de lo cotidiano. I. Artes de hacer. México: OAC.

Freire, P. (1992). Pedagogía da esperanza. Río de Janeiro: Paz e terra.

Girón, C. (2013). Propuesta pedagógica de articulación entre academia y movimiento social: una apuesta estética y política por la educación activa y participativa en derechos humanos. En C. Castillejo \& F. Reyes (eds.), Violencia, memoria y sociedad: debates y agendas en la Colombia actual (pp. 623-648). Bogotá: USTA.

GMH - Grupo de Memoria Histórica (2011). La huella invisible de la guerra. Desplazamiento Forzado en la comuna 13. Bogotá: Semana.

Grupo Lazos Sociales y Culturas de Paz (2014). Protocolo de participación efectiva de las víctimas. Recuperado de http://www.viva.org.co/publicaciones/cartilla_protocolo/.

Hincapié, E. (2019). Comunidades trasformadoras de ciudad. Medellín: Universidad Pontificia Bolivariana.

Montejano, M. (2008). Processes of consolidation and differentiation of informal settlements: case study Ciudad Nezahualcóyotl, Mexico City. Tesis doctoral (Architektur und Stadtplanung). Stuttgart: University of Stuttgart. Recuperado de http://nbnresolving.de/urn:nbn:de:bsz:93-opus-35754.

Montero, M. (2010a). La construcción de teoría en la praxis comunitaria: la relación entre acción y explicación. En A. E. Hincapié (comp.), Sujetos políticos y acción comunitaria. Medellín: Universidad Pontificia Bolivariana.

_ (2010b). De la ética del individualismo a la ética de la otredad: la noción de otro y la liberación de la psicología. Postconvencionales, (1), pp. 83-97.

Montoya, V. (2012). Memorias en fuga. Violencias y desarraigo en Colombia. Barcelona: Universitat de Barcelona.

MOVICE, FCSPP y CCAJAR (2009). Sin justicia y sin paz. Verdad fragmentada, reparación ausente. Bogotá. Recuperado de http://memoriaydignidad.org/memoriaydignidad/index.php/site-administrator/extradicion-y-sus-secuelas/investigacionesrelacionadas.

Pécaut, D. (2004). Memoria imposible, historia imposible, olvido imposible. En R. Belay; J. Bracamonte; C. I. Degregori \& J. Joinville (eds.), Memorias en conflicto. Aspectos de la violencia política contemporánea (pp. 87-104). Arequipa: Biblioteca Nacional del Perú. 
Piper, I.; Fernández, R. e Íñiguez, L. (2013). Psicología social de la memoria: espacios y políticas del recuerdo. Psykhe, 22(2), pp. 19-31. Recuperado de http://www.redalyc. org/pdf/967/96728593003.pdf.

Prigogine, I. (2006). El nacimiento del tiempo. Buenos Aires: Tusquets.

Ricoeur, P. (2004). La memoria, la historia, el olvido. Buenos Aires: Fondo de Cultura Económica.

Rieff, D. (2012). Contra la memoria. Barcelona: Debate.

Rojas, M. B. (2015). Babilonia y el teatro de la máquina parásita. Metáforas en el tiempo para pensar la ciudad latinoamericana. Medellín: Universidad Nacional de Colombia.

Sassen, S. (2015). Expulsiones. Brutalidad y complejidad de la economía global. Buenos Aires: Katz.

Uribe, M. T. (2011). Estado y sociedad frente a las víctimas de la violencia. Revista Desde la Región. Memoria, (54), pp. 37-48.

Vázquez, F. (2001). La memoria como acción social. Relaciones, significado e imaginario. Barcelona: Paidós.

Velásquez, C. (2011). La política de mejoramiento integral en los barrios de Medellín. ¿Reconquista del territorio por parte del Estado? Revista Kavilando 2, 8(3), pp. 72-78.

Wallerstein, I. (coord.) (2006). Abrir las ciencias sociales. Informe de la Comisión Gulbenkian para la reestructuración de las ciencias sociales. Ciudad de México: Siglo XXI.

Wallerstein, I. (1997). El espaciotiempo como base del conocimiento. Análisis político, (32), pp. 4-18.

(1999). El fin de las certidumbres en ciencias sociales. México: Universidad Nacional Autónoma. 